\title{
A importância da cooperação sul-sul em saúde no processo de implantação da Rede Latino-americana de Banco de Leite Humano
}

The importance of health cooperation in the implementation process of the Latin American Human Milk Bank Network

La importancia de la cooperación en salud en el proceso de implantación de la RedLatinoamericana de Banco de Leche Humana

RESUMO. Objetivo: Este estudo tem como objetivo analisar a importância do modelo de cooperação sul-sul para a implantação da Rede Latino-americana de Banco de Leite Humano e as ações desempenhadas pelo Brasil neste processo de implantação. Metodologia: Tratou-se de uma pesquisa com a utilização da análise bibliográfica e documental, para a compreensão da cooperação estruturante. Sendo realizada a busca nas bases de dados do SciELO, e LILACS, e no site da Rede Global de Banco de Leite da Fundação Oswaldo Cruz. Foram selecionados 10 artigos e cinco documentos oficiais. Resultados: Percebe-se que a trajetória de cooperação entre os países teve sua construção marcada por eventos e acordos, que permitiram a estruturação da Rede Global de Leite Humano, maior articuladora para o sucesso da política pública em amamentação no Brasil, enfrentando da mortalidade infantil, e afirmando o protagonismo feminino que movimenta todas as ações que cooperam para a redução da mortalidade infantil. Conclusão: A estratégia mantém um perfil solidário entre os países pactuados, pois o objetivo de redução da mortalidade é enfrentado como experiência exitosa.

Palavras-chave: Banco de Leite. Diplomacia em Saúde. Cooperação Sul-Sul.

ABSTRACT. Objective: This study aims to analyze the importance of the South-South cooperation model for the implementation of the Latin American Network of Human Milk Bank and the actions carried out by Brazil in this implementation process. Methodology: It is a research with the use of bibliographical and documentary analysis, for the understanding of structuring cooperation. The search was carried out in the databases of Scielo, and LILACS, and in the website of the Global Network of Milk Bank of the Oswaldo Cruz Foundation. We selected 10 articles and five official documents. Results: It is noticed that the cooperation path between the countries was built by events and agreements, which allowed the structuring of the Global Network of Human Milk, the main articulator for the success of the public policy on breastfeeding in Brazil, facing infant mortality, and affirming the female protagonism that moves all actions that cooperate to reduce infant mortality. Conclusion: The strategy maintains a solidarity profile between the agreedments countries, because the objective of mortality decrease is confronting as a successful experience.

Keywords: Milk Bank. Health Diplomacy. South-South Cooperation.

RESUMEN. Objetivo: Este estudio tiene como objetivo analizar la importancia del modelo de cooperación sur-sur para la implantación de la Red Latinoamericana de Banco de Leche

\footnotetext{
${ }^{1}$ Barachel em enfermagem Especialista em ginecologia e Obstetricia Especialista em Direito Sanitário.Servidora Publica da Secretaria de Saúde do Distrito Federal. E-mail: marlenefiocruz@gmail.com
} 
Humana y las acciones desempeñadas por Brasil en este proceso de implantación. Metodología: Se trata de una investigación con la utilización del análisis bibliográfico y documental, para la comprensión de la cooperación estructurante. Se realizó la búsqueda en las bases de datos de Scielo, y LILACS, y en el sitio de la Red Global de Banco de Leche de la Fundación Oswaldo Cruz. Se seleccionaron 10 artículos y cinco documentos oficiales. Resultados: Se percibe que la trayectoria de cooperación entre los países tuvo su construcción marcada por eventos y acuerdos, que permitieron la estructuración de la Red Global de Leche Humana, mayor articuladora para el éxito de la política pública en lactancia en Brasil, enfrentándose a la mortalidad infantil, y afirmando el protagonismo femenino que mueve todas las acciones que cooperan para la reducción de la mortalidad infantil. Conclusión: La estrategia mantiene un solidario perfil entre los países pactados, porque el objetivo de reducir la mortalidad se enfrentado como una experiencia exitosa.

Palabras-Ilave: Banco de Leche. Diplomacia en la salud. Cooperación Sur-Sur.

\section{Introdução}

O surgimento da cooperação internacional em saúde emerge devido a resultados do conhecimento sobre as doenças infecciosas e as tecnologias de transporte do século XIX. A partir de 1851, tratados foram assinados e organizações internacionais foram criadas para fortalecer a cooperação internacional em saúde (1).

Em 1948, foi criada a Organização Mundial de Saúde (OMS) que por sua vez editou o Regulamento Sanitário Internacional (RSI). Essas ações convergiram para os primeiros processos, regras e instituições para governança em saúde global (1).

A cooperação para o desenvolvimento tem mostrado relevância nas relações internacionais; o Brasil tem participado da cooperação da evolução técnica desde seus primórdios, quando se deu a partir de 1970, o Brasil foi chamado a contribuir nos esforços da cooperação sul-sul, também conhecida como cooperação horizontal (2).

Sendo assim, a cooperação sul-sul, um órgão subsidiário da Assembleia Geral da ONU, "que se tornou uma importante entidade normativa em matéria de cooperação entre países em desenvolvimento" (3), ocorre uma cooperação entre eles, de forma solidária, sendo ela de natureza estruturante e técnica.

Já a cooperação norte-sul faz parte da cooperação internacional para o desenvolvimento que abrange os países beneficiários das cooperações prestadas. A principal diferença entre a cooperação norte-sul e sul-sul está nas suas características metodológicas, destacando-se pelo autor, "a análise das promessas e dos discursos dos governos dos países em desenvolvimento, das denúncias e propostas de parcerias dos atores não governamentais" (4). 
Esta cooperação norte-sul são os países do norte que fazem uma inferência nos países do sul, composta por países desenvolvidos (Estados Unidos, Canadá e países da Europa) que realizam cooperação nos países do sul. Observa-se que entre os países de primeiro mundo que fazem esta cooperação em países subdesenvolvidos não existe uma relação de igualdade e ocorre uma relação de imposição (4).

A cooperação técnica horizontal brasileira desenvolve projetos tais como os que envolvem transferência de princípios, disseminação de conhecimentos técnicos, experiências bem-sucedidas, capacitação de recursos humanos e fortalecimento organizacional. A horizontalidade com ênfase no intercâmbio de experiências, compartilhamentos de resultados e responsabilidade assim como a aprendizagem conjunta (2).

Constitui a cooperação técnica que tem como objetivo o fortalecimento institucional de parceiros, sem fins lucrativos e desvinculados de interesses comerciais, a cooperação técnica busca compartilhar experiências com os países parceiros. Essa modalidade de cooperação tem crescido e desenvolvido mantendo relações com a América Latina, Caribe e África, com ações pontuais na Ásia (Timor Leste) Afeganistão, Uzbequistão, Oriente Médio (Líbano e território Palestinos) e Oceania (5).

A iniciativa em cooperar emerge de uma necessidade para a Ajuda Oficial do Desenvolvimento (AOD) reduzindo a oferta e doadores oficiais que dentro de uma perspectiva de pressão mundial e variações de mudanças econômicas e políticas ofertam de forma imperativa em seu modelo de assistência vertical (6).

Como salienta Almeida (2010) esse tipo de cooperação tornou-se um instrumento importante para a estratégia de cooperação sul-sul e ganhou novos contornos políticos, econômicos e estratégicos. O princípio horizontalidade representou uma alternativa à "verticalidade" - transferências unilaterais de "pacotes prontos" - então conhecidos como ajuda internacional norte-sul (7).

Os enfoques de cooperação em saúde têm variado acompanhando tendências para o desenvolvimento. Nas décadas de 1960 a 1970 estava focada em sistemas de atenção primária a saúde, em meados de 1970, a atenção foi desviada para assistência médica. Porém, em 1980, em meio à crise econômica agravaram a pobreza e a desigualdade, a disseminação da epidemia do HIV juntamente com outras doenças traz uma sobrecarga para os países de renda média e baixa, com a chegada do Milênio o cenário era bem mais 
complexo e a percepção era de iniciativa internacional e global, militando melhoria para a saúde das populações (7).

Alguns questionamentos têm surgido na esfera internacional fazendo uma reflexão crítica a respeito das iniciativas do Brasil em liderar projetos bilaterais. A crítica está pautada no que diz respeito à cooperação sul-sul e se o Brasil como um protagonista em desenvolvimento está fazendo uso do modelo meramente para exportar suas ideias e tornarse visível no âmbito internacional, tornando o modelo sul verticalizado, Puente (2010) faz essa crítica ao modelo adotado pelo Brasil relatando um foco muito mais de inserção política externa do que meramente de uma cooperação solidária (7).

A pesquisa norteou-se em torno da utilização do modelo de cooperação técnica internacional brasileira de implantação da Rede de Banco de Leite para América Latina, denominada estruturante, calcada num planejamento estratégico conjunto com os países que cooperam entre si, no lugar da oferta de ajuda, trata-se de compartilhar conhecimentos e soluções com as instituições parceiras, rompendo com a tradicional transferência passiva de conhecimento integrado, desenvolvimento de recursos humanos e outras capacidades, utilizando o planejamento estratégico na perspectiva de conhecimento de rede de cooperação.

Supõe-se que o Brasil desempenha um importante papel com base em sua experiência de banco de leite e a cooperação sul-sul foi capaz de potencializar essa experiência com base na troca entre países, manifestando seu caráter solidário, pois evidencia uma política de implantação de baixo custo, onde a maior protagonista é a mulher que faz a doação do seu leite.

A expressão feminina em todos os setores da sociedade tem sido crescente. As mulheres têm assumido um papel relevante em todas as áreas, inclusive na política pública, contribuindo de maneira extraordinária para o avanço e melhoria da saúde e nesse contexto de cooperação em Banco de leite humano o avanço está ligado com a presença de mulheres doadoras que em seu momento maternal compartilha o seu leite.

Neste sentido, este estudo teve como objetivo analisar a importância do modelo de cooperação sul-sul para a implantação da Rede Latino-americana de Banco de Leite Humano e as ações desempenhadas pelo Brasil neste processo de implantação. 


\section{Metodologia}

Pesquisa de caráter exploratório, com a utilização de técnicas de análise bibliográfica e documental, para buscar a compreensão da cooperação estruturante da Rede Latino Americana de Banco de Leite, atendendo aos objetivos do estudo.

As informações para a análise bibliográfica foram obtidas através dos Descritos em Ciência da Saúde (DeCS), utilizando-se os seguintes descritores: Banco de leite, Diplomacia em saúde, cooperação sul-sul, e no site da Agência Brasileira de Cooperação (ABC). As buscas foram realizadas nas bases de dados do SciELO e LILACS. Como critérios de inclusão foram utilizadas publicações compreendidas entre 2007 a 2017, em português, inglês e espanhol, que estejam disponíveis na íntegra e que atendam o objetivo do estudo. Como critérios de exclusão, publicações pagas, que disponibilize apenas resumo (quadro 1).

Para a análise documental foi utilizado site da Rede Global de Banco de Leite que está inserida no site da Fundação Oswaldo Cruz (Fiocruz).

\section{Resultados/Discussão}

A amostra final foi composta de 10 artigos. A seleção dos artigos baseada na busca feita pelos descritores, realizado o cruzamento (tabela 1), nove foram selecionados no SciELO e um no LILACS. E os dados acerca dos 10 artigos selecionados (quadro 1) foram organizados de acordo com as seguintes informações: título, autores, base de dados, periódico e ano. Já os 5 documentos analisados foram catalogados de acordo com os autores, título e ano de publicação (quadro 2).

Tabela 1 - Artigos encontrados e selecionados nas bases de dados associando os descritores, utilizando o operador booleano and.

\begin{tabular}{c|c|c|c|c}
\hline \multirow{2}{*}{$\begin{array}{c}\text { DESCRITORES } \\
\text { Associando dois }\end{array}$} & Encontrados & Selecionados & Encontrados & Selecionados \\
\cline { 2 - 5 } & 15 & 8 & 15 & 1 \\
$\begin{array}{c}\text { Diplomacia em saúde } \\
\begin{array}{c}\text { AND cooperação sul- } \\
\text { sul }\end{array}\end{array}$ & 1 & 1 & & 0 \\
\hline $\begin{array}{c}\text { Banco de leite AND } \\
\text { cooperação sul-sul }\end{array}$ & 15 & 0 & 0 & 0 \\
\hline $\begin{array}{c}\text { Banco de leite AND } \\
\text { Diplomacia em saúde }\end{array}$ & 0 & & 2 & \\
\hline
\end{tabular}

Fonte: Elaborada própria baseado nas informações levantadas pela busca nas bases de dados. 


\section{Quadro 1 - Informações sobre os artigos selecionados}

\begin{tabular}{|c|c|c|c|c|}
\hline Título do Artigo & Objetivo & Temática & Autores & $\begin{array}{l}\text { Periódico } \\
\text { Ano de } \\
\text { Publicação } \\
\text { Base de } \\
\text { dados }\end{array}$ \\
\hline $\begin{array}{l}\text { Cooperação técnica } \\
\text { internacional em } \\
\text { bancos de leite } \\
\text { humano: um estudo } \\
\text { da horizontalidade } \\
\text { nos projetos } \\
\text { bilaterais }\end{array}$ & $\begin{array}{lr}\text { Estudar a construção } \\
\text { dos vínculos entre os } \\
\text { participantes r da } \\
\text { cooperação técnica } \\
\text { internacional } & \text { em } \\
\text { Banco de } & \text { Leite } \\
\text { Humano } & \\
\text { desenvolvida } & \text { na } \\
\text { Fiocruz. } & \end{array}$ & $\begin{array}{l}\text { O reconhecimento de } \\
\text { que a cooperação } \\
\text { técnica internacional de } \\
\text { BLH praticada pela } \\
\text { Fiocruz em uma ação } \\
\text { integrada com a } \\
\text { Agência Brasileira de } \\
\text { Cooperação é um } \\
\text { exemplo exitoso na } \\
\text { cooperação sul-sul. }\end{array}$ & $\begin{array}{l}\text { Rabuffetti } \\
\text { AG. }\end{array}$ & $\begin{array}{l}\text { Tese em } \\
\text { Português } \\
2014 . \\
\text { LILACS }\end{array}$ \\
\hline 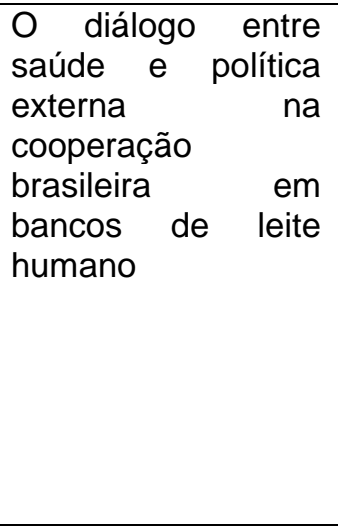 & $\begin{array}{lr}\text { Compreender } & 0 \\
\text { motiva o Brasil a } \\
\text { promover os bancos } \\
\text { de } & \text { leite } \\
\text { internacionalmente. }\end{array}$ & $\begin{array}{l}\text { Aborda que a } \\
\text { amamentação é a } \\
\text { principal alimentação } \\
\text { do neonato, mas que } \\
\text { na impossibilidade, o } \\
\text { banco de leite surge } \\
\text { como alternativa. } \\
\text { Culminando em } \\
\text { diversos projetos de } \\
\text { cooperação } \\
\text { internacional para } \\
\text { implantação da rede de } \\
\text { bancos de leite. }\end{array}$ & $\begin{array}{l}\text { Pittas TM, } \\
\text { Dri CF. }\end{array}$ & $\begin{array}{l}\text { Ciência \& } \\
\text { Saúde } \\
\text { Coletiva, } \\
2017 . \\
\text { SCIELO }\end{array}$ \\
\hline $\begin{array}{l}\text { Um olhar sobre a } \\
\text { Cooperação Sul-Sul } \\
\text { em Saúde }\end{array}$ & $\begin{array}{lr}\text { Análise } & \text { da } \\
\text { experiência } & \text { da } \\
\text { cooperação sul-sul. }\end{array}$ & $\begin{array}{l}\text { Breve revisão sobre o } \\
\text { significado } \\
\text { cooperação técnica no } \\
\text { seio da } \\
\text { ressaltando } \\
\text { dimensão politica. }\end{array}$ & $\begin{array}{l}\text { Santana } \\
\text { JP. }\end{array}$ & $\begin{array}{l}\text { Ciênc. } \\
\text { Saúde } \\
\text { coletiva; } \\
2011 . \\
\text { LILACS }\end{array}$ \\
\hline 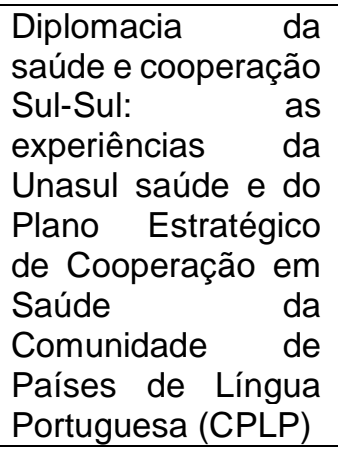 & $\begin{array}{lr}\text { Apresentar } & \text { as } \\
\text { principais } & \\
\text { características } & \text { da } \\
\text { cooperação } & \\
\text { internacional } & \text { em } \\
\text { saúde. } & \end{array}$ & $\begin{array}{l}\text { Abordagem da } \\
\text { cooperação sul-sul e } \\
\text { como se desenvolve } \\
\text { particularmente entre } \\
\text { os países da América } \\
\text { do Sul e entre os } \\
\text { Países africanos de } \\
\text { língua oficial } \\
\text { portuguesa. }\end{array}$ & $\begin{array}{l}\text { Buss, } \\
\text { PM; } \\
\text { Ferreira, } \\
\text { JR. }\end{array}$ & $\begin{array}{l}\text { RECIIS } \\
\text { (Online); } \\
2017 . \\
\text { LILACS }\end{array}$ \\
\hline $\begin{array}{lr}\text { Paradoxos } & \text { da } \\
\text { cooperação } & \text { em } \\
\text { saúde } & \end{array}$ & $\begin{array}{l}\text { Refletir sobre saúde e } \\
\text { desenvolvimento, e } \\
\text { apresentar uma } \\
\text { revisão histórica. }\end{array}$ & $\begin{array}{l}\text { A cooperação Sul-sul } \\
\text { em saúde como objeto } \\
\text { central de análises e } \\
\text { debates no Núcleo de } \\
\text { Estudos sobre Bioética } \\
\text { e Diplomacia em } \\
\text { Saúde. }\end{array}$ & $\begin{array}{l}\text { Santana } \\
\text { JP. }\end{array}$ & $\begin{array}{l}\text { Rev. hum. } \\
\text { méd; } 2013 . \\
\text { LILACS }\end{array}$ \\
\hline $\begin{array}{l}\text { A agenda de } \\
\text { Cooperação Sul-Sul }\end{array}$ & $\begin{array}{l}\text { Analisar o processo } \\
\text { de formulação da }\end{array}$ & $\begin{array}{l}\text { Enfoque teórico sobre } \\
\text { a cooperação sul-sul }\end{array}$ & $\begin{array}{l}\text { Carrillo } \\
\text { Roa, }\end{array}$ & $\begin{array}{l}\text { Tese em } \\
\text { Português }\end{array}$ \\
\hline
\end{tabular}




\begin{tabular}{|c|c|c|c|c|}
\hline $\begin{array}{l}\text { em Saúde do Fórum } \\
\text { IBAS - Índia, Brasil } \\
\text { e África do Sul. }\end{array}$ & $\begin{array}{l}\text { agenda de } \\
\text { cooperação bi ou } \\
\text { trilateral em saúde do } \\
\text { Fórum de Diálogo } \\
\text { Índia, Brasil e África } \\
\text { do Sul no período de } \\
2003-2013 \text { e seus } \\
\text { respectivos } \\
\text { desdobramentos. }\end{array}$ & $\begin{array}{l}\text { na saúde e questões } \\
\text { relacionadas à } \\
\text { formulação de agendas } \\
\text { e ao processo decisório } \\
\text { no âmbito das politicas } \\
\text { públicas. }\end{array}$ & & $\begin{array}{l}2014 . \\
\text { LILACS }\end{array}$ \\
\hline $\begin{array}{l}\text { Panorama da } \\
\text { cooperação } \\
\text { internacional em } \\
\text { saúde em países da } \\
\text { América do Sul }\end{array}$ & $\begin{array}{l}\text { Descrever a ação de } \\
\text { organizações } \\
\text { internacionais e sua } \\
\text { atuação em saúde. }\end{array}$ & $\begin{array}{l}\text { O desenvolvimento das } \\
\text { relações internacionais } \\
\text { sobre cooperação } \\
\text { internacional e } \\
\text { culminaram em criação } \\
\text { de blocos regionais de } \\
\text { cooperação. }\end{array}$ & $\begin{array}{l}\text { Perez, F } \\
\text { A. }\end{array}$ & $\begin{array}{l}\text { Tese em } \\
\text { Português } \\
2012 . \\
\text { LILACS }\end{array}$ \\
\hline $\begin{array}{lr}\text { Diplomacia } & \mathrm{e} \\
\text { cooperação } & \mathrm{em} \\
\text { saúde: } & \text { uma } \\
\text { perspectiva } & \text { da } \\
\text { Fiocruz } & \end{array}$ & $\begin{array}{lr}\text { Estudar } & \text { a } \\
\text { implementação } & \text { de } \\
\text { políticas para } & 0 \\
\text { desenvolvimento } \\
\text { global tal como a } \\
\text { agenda } 2030 \text { e os } \\
\text { ODS. }\end{array}$ & $\begin{array}{l}\text { Relações entre a } \\
\text { política externa e ações } \\
\text { da Fiocruz no campo } \\
\text { das } \\
\text { internacionais. }\end{array}$ & $\begin{array}{l}\text { Fonseca } \\
\text { LE, Buss } \\
\text { P. }\end{array}$ & $\begin{array}{ll}\text { Livro } & 30 \\
\text { anos } & \text { de } \\
\text { ABC } & \\
2017 & \end{array}$ \\
\hline $\begin{array}{lr}\text { Cooperação } & \\
\text { Técnica } & \\
\text { internacional } & \text { em } \\
\text { banco de leite- } \\
\text { Fiocruz/ABC uma } \\
\text { boa prática de } \\
\text { cooperação } \\
\text { internacional? }\end{array}$ & $\begin{array}{lrr}\text { Identificar a } & \text { ação } \\
\text { Banco de } & \text { Leite } \\
\text { Humano } & \text { como } \\
\text { estratégia capaz de } \\
\text { contribuir para a } \\
\text { redução ra da } \\
\text { mortalidade infantil }\end{array}$ & $\begin{array}{l}\text { Rede latino-americana, } \\
\text { uma estratégia para } \\
\text { enfrentar os altos } \\
\text { índices de mortalidade } \\
\text { infantil agravado pelo } \\
\text { panorama global, uma } \\
\text { experiência exitosa no } \\
\text { combate a mortalidade } \\
\text { infantil a garantia de } \\
\text { direito à saúde das } \\
\text { crianças. }\end{array}$ & $\begin{array}{l}\text { Aprigio J } \\
\text { et al. }\end{array}$ & $\begin{array}{l}\text { Livro } \\
\text { anos } \\
\text { ABC } \\
2017\end{array}$ \\
\hline $\begin{array}{l}\text { O papel do Brasil na } \\
\text { cooperação sul-sul: } \\
\text { um estudo analítico } \\
\text { e histórico }\end{array}$ & $\begin{array}{lr}\text { Compreender } & \text { a } \\
\text { relevância e } & \text { a } \\
\text { maneira que a } & \text { a } \\
\text { cooperação sul-sul } \\
\text { apresenta para } \\
\text { alcançar o progresso } \\
\text { e os objetivos de } \\
\text { desenvolvimento } \\
\text { acordados } \\
\text { internacionalmente. }\end{array}$ & $\begin{array}{l}\text { A cooperação sul-sul } \\
\text { como um instrumento } \\
\text { de desenvolvimento } \\
\text { entre os países do } \\
\text { Hemisfério Sul em face } \\
\text { aos seus desafios } \\
\text { comuns, a crescente } \\
\text { visibilidade do Brasil no } \\
\text { campo da cooperação } \\
\text { em saúde. }\end{array}$ & Chediek J & $\begin{array}{l}\text { Livro } \\
\text { anos } \\
\text { ABC } \\
2017\end{array}$ \\
\hline
\end{tabular}

Fonte: Elaborada pela autora baseado nos artigos selecionados nas bases de dados. 
Quadro 2- Documentos oficiais selecionados para discussão da pesquisa e catalogados de acordo com os autores, título e ano de publicação.

\begin{tabular}{|c|c|c|c|}
\hline Título & $\begin{array}{l}\text { Documentos } \\
\text { Oficiais }\end{array}$ & Síntese do documento & Ano \\
\hline Carta de Brasília & $\begin{array}{l}\text { Documento } \\
\text { Tipo acordo de } \\
\text { resultados }\end{array}$ & $\begin{array}{l}\text { Representantes dos Ministérios da Saúde de países da } \\
\text { América Latina assumiram os seguintes compromissos } \\
\text { visando o fortalecimento de ações na área de lactância } \\
\text { materna. Um marco histórico da América Latina. }\end{array}$ & 2005 \\
\hline Carta de Brasília & $\begin{array}{l}\text { Documento- } \\
\text { Tipo acordo de } \\
\text { resultados }\end{array}$ & $\begin{array}{l}\text { Representantes dos setores de saúde e de proteção } \\
\text { social dos governos e da sociedade civil, se reuniram } \\
\text { para ratificar os compromissos assumidos na carta } \\
2005 \text {, reconhecer que os Bancos de leite são uma } \\
\text { estratégia para ODM, reconhecer a importância da } \\
\text { criação dos bancos de leite e reconhecer os avanços } \\
\text { que os países alcançaram após a implementação dos } \\
\text { Bancos de Leite Humano. }\end{array}$ & 2010 \\
\hline $\begin{array}{ll}\text { Proibição } & \text { da } \\
\text { comercialização } \\
\text { do leite humano } \\
\text { nos } & \text { estados } \\
\text { partes. } & \end{array}$ & $\begin{array}{l}\text { Portaria } n^{\circ} 2468 \\
\text { de } 31 / 08 / 2010\end{array}$ & $\begin{array}{l}\text { Assegura que o aleitamento é imprescindível para a } \\
\text { criança, reduz a morbimortalidade, a prioridade da } \\
\text { disposição de leite humano em quantidade e } \\
\text { qualidade para as crianças, e assegurar o acesso } \\
\text { gratuito ao leite humano, subprodutos e/ou derivados. }\end{array}$ & 2011 \\
\hline $\begin{array}{l}\text { Instituição do Dia } \\
\text { MERCOSUL de } \\
\text { doação de leite } \\
\text { humano }\end{array}$ & $\begin{array}{ll}\text { Documento de } \\
\text { Aprovação de } \\
\text { data }\end{array}$ & $\begin{array}{l}\text { Instituição do Dia da doação voluntária, gratuita e } \\
\text { altruísta do leite humano. Tal documento aborda as } \\
\text { considerações acerca das ações de saúde nos } \\
\text { primeiros meses de vida, a promoção, proteção e } \\
\text { apoio da amamentação materna. Também sobre a } \\
\text { doação de leite humano no âmbito do MERCOSUL, e } \\
\text { o cumprimento dos ODM. }\end{array}$ & 2012 \\
\hline Carta de Brasília & $\begin{array}{l}\text { Documento- } \\
\text { Tipo acordo de } \\
\text { resultados }\end{array}$ & $\begin{array}{l}\text { Representantes dos setores de saúde e de proteção } \\
\text { social dos governos e da sociedade civil dos países e } \\
\text { de organismos internacionais se reuniram para } \\
\text { considerar os compromissos das cartas de Brasília } \\
2005 \text { e } 2010 \text {, e Montevidéu 2014. Da Rede de Bancos } \\
\text { de Leite Humano como iniciativa que contribuiu para o } \\
\text { desenvolvimento, redução da morbimortalidade } \\
\text { infantil, promoção do aleitamento materno e os } \\
\text { avanços alcançados. Além de considerar os Bancos } \\
\text { de Leite Humano como função estratégica das } \\
\text { políticas públicas. }\end{array}$ & 2015 \\
\hline
\end{tabular}

Fonte: Elaborada pela autora baseado nos documentos utilizados.

\section{A Expansão da Rede Banco de leite Humano e a Agência Brasileira de Cooperação}

A Rede Latino-Americana de Bancos de Leite Humano teve seu início em 2005, como ação estratégica para o enfrentamento da mortalidade e morbimortalidade infantil. Em 2007, o Governo brasileiro apresentou o projeto Apoio Técnico para a implantação da Rede lbero Americano de Leite Humano e para que essa execução e condução fossem instaladas. Foi 
desenvolvida uma secretaria executiva na unidade da Fiocruz, junto ao Instituto Nacional de Saúde da Mulher da Criança e Adolescente Fernandes Figueira (8).

A Rede Latino Americana de Leite Humano é um programa multilateral na região IberoAmericana que visa apoiar a implantação de no mínimo um banco de leite humano em cada país como componente estratégico para alcançar os Objetivos de Desenvolvimento do Milênio (ODM), com ênfase na redução da mortalidade infantil (8).

A implantação de Banco de Leite humano na América Latina está pautada no modelo estruturante de horizontalidade, que se fundamenta na construção de capacidades para o desenvolvimento, nestes aspectos são abordados: formação de recursos humanos, desenvolvimento institucional, fortalecimento organizacional rompendo com o modelo de transferência passiva para o conhecimento de tecnologias (7).

A Agência Brasileira de Cooperação $(A B C)$ vinculada ao Ministério das Relações Exteriores (MRE) junto a Fundação Oswaldo Cruz (Fiocruz) foram as responsáveis pela expansão da Rede em toda a América Latina. O apoio da Agência foi fundamental para que ocorresse a cooperação sul-sul, a ABC é responsável por coordenar, negociar a cooperação internacional, também contribui para arregimentação e mobilização nacional de instituição executora e entidades cooperantes, o processo de articulação aconteceu entre a $A B C$, Ministério da Saúde e a Fiocruz, logo após o primeiro documento intitulado carta de Brasília em 2005, onde o Brasil compartilha suas experiências por meio de cooperação técnica bilateral (9).

A trajetória de cooperação entre os países deve-se a uma construção marcada por eventos e acordos entre os países participantes, o primeiro acordo a ser assinado pelos Estados é a carta de Brasília (9).

No que diz respeito à implantação da Rede de Banco de Leite na América Latina, os resultados foram expressamente positivos, pois a amamentação trata do direito à saúde da criança e prevenção em saúde na vida adulta. Partindo do princípio que o leite materno é alimento mais completo que um recém-nascido pode receber e que a matéria prima não é comercializada e não tem custo algum, neste caso, não temos relação comercial e sim uma relação de solidariedade onde doadoras se movimentam voluntariamente a atender as demandas. 
A política de saúde em amamentação não possui o mérito sem a participação das doadoras, que no seu momento de produção láctea são sensibilizadas a participar dessa grande Rede de Banco de Leite que está no Brasil e em parte do mundo.

Nesse contexto, há uma busca conjunta pelo desenvolvimento a partir das garantias de do direito a saúde infantil em Estados do Sul Global com baixa desigualdade relativa nesse quesito (10).

Evidente que toda proposição bilateral gera êxitos e nesse contexto internacional o Brasil tem colocado suas políticas como significativas na obtenção de objetivos globais como os da ODM, permitindo no país autonomia de realizações de políticas internas com grande capacidade de liderança é o caso da política pública em amamentação (10).

\section{A Implantação da Rede de Banco Leite: uma trajetória histórica}

A implantação de Rede Brasileira de Bancos de Leite Humano (RBLH-BR) ocorreu com apoio da Organização Pan-Americana de Saúde (Opas) no ano de 2003, após dois anos no II Congresso Internacional de Bancos de Leite Humano em 2005, no qual 2.500 profissionais e 13 países (América Latina, Estados Unidos e Inglaterra) nesse encontro um grupo de trabalho desenvolveu e elaborou um protocolo em dois exemplares nos idiomas português e espanhol, esse protocolo foi denominado Carta de Brasília (11).

A Carta de Brasília foi nomeada o primeiro documento assinado entre os Estados a pactuar sobre a política da criação da Rede Latino-Americana de Bancos de Leite Humano. Esse documento foi assinado no dia 19 de maio de 2005, o Projeto da Rede LatinoAmericana de Bancos de Leite Humano foi firmado na experiência do banco de Leite brasileiro expandindo o modelo brasileiro em outros países - Venezuela, Uruguai, Argentina, Equador e Cuba. A Cooperação Internacional ocorre através de Atos Internacionais formalizados e regidos pelo Direito Internacional (11).

Em 9 de junho de 2008, mediante um acordo multilateral foi instalada na Fundação Oswaldo Cruz, a Secretaria Executiva da Rede Ibero-Americana de Bancos de Leite Humano, responsável por sediar o Programa de Apoio Técnico para Implantação da Rede Ibero-Americana de Bancos de Leite Humano (Programa IberBLH), nesse acordo sete países assinaram o termo. Foi aprovado o Programa Cumbre de Rede de Bancos de Leche Humana com base no modelo brasileiro coordenado pela Fiocruz, em novembro de 2007. Reuniram-se 22 Chefes de Estado e Governo de nações portuguesa e espanhola da 
América Latina e Europa, a Cumbre sediada no Chile tendo como tema central: "Coesão social e políticas sociais para atingir sociedades mais inclusivas na lbero-América" (11).

Em 2008, segundo a Organização Pan-Americana de Saúde, aleitamento materno e a alimentação complementar foi definido como duas das intervenções mais eficazes para prevenir a mortalidade infantil. A cooperação técnica "Brasil, Honduras e Equador - Bancos de Leite Humano" foi desenvolvida em 2008, com o objetivo de contribuir com a redução da mortalidade infantil, apoiando políticas e trazendo respostas institucionais e comunitárias para fortalecer a política aleitamento materno e a capacidade de resposta do estado, através da cooperação sul-sul (11).

Em setembro de 2010, governos e representantes da saúde e da sociedade civil do continente africano e ibero-americano participaram de grupo de trabalho no $\mathrm{V}$ Congresso Brasileiro de Bancos de Leite Humano/ I Congresso Ibero-Americano de Bancos de Leite Humano/ I Fórum de Cooperação Internacional em Bancos de Leite Humano, realizado no período de 27 a 30 de setembro de 2010, em Brasília, os Estados envolvidos assinaram uma carta assumindo a continuidade do trabalho e resgatando a estratégias da carta assinada em 2005 (11).

As diretrizes e compromissos para o futuro da Rede Global de Bancos de Leite Humano (RBLH), bem como esta denominação, foram pensados cinco anos depois. No período de 21 a 25 de setembro de 2015, foi realizado em Brasília, o II Fórum ABC/Fiocruz/Ministério da Saúde de Cooperação Internacional em Bancos de Leite Humano, com a participação de 22 países. A Carta de Brasília 2015 foi acordada e assinada durante o evento. A Rede Latino Americana transpôs a barreira do continente americano e passou a cooperar com países de língua portuguesa no continente africano e países da Europa, Portugal e Espanha (11).

Entre os acordos surgiram à nova nomenclatura destinada da Rede Latino-lbero-AfroAmericana de Bancos de Leite Humano para Rede Global de Bancos de Leite Humano. Foi oficializado em 19 de maio como Dia Mundial de Doação de Leite Humano na Organização Mundial da Saúde (OMS); além do compromisso de promover condições que ampliem o acesso ao leite humano, a fim de reduzir as mortes evitáveis de recém-nascidos e prevenir a ocorrência de doenças crônicas não transmissíveis, pontos inclusos nas metas dos Objetivos de Desenvolvimento Sustentável (11). 


\section{Cooperação sul-sul para a implantação da Rede Latino-americana de Banco de Leite Humano.}

Nos últimos anos, o Brasil vem desempenhando um papel ativo no cenário internacional, resultado de sua inserção nesse cenário e das diretrizes de sua política externa no campo da ciência e saúde. Considerado um país de nível intermediário e uma potência geopolítica regional, o Brasil assume cada vez mais, funções e responsabilidades que correspondem ao papel a que aspira ou que desempenha internacionalmente. Dada sua superfície geográfica, seu contingente populacional, seu nível de desenvolvimento econômico e a riqueza de seus recursos naturais, o país reivindica posição de relevância na política internacional (12) (13).

Isso implica uma autopercepção do país com relação ao seu protagonismo no exterior, ao papel da diplomacia em saúde e de sua elite na política externa, assim como seu reconhecimento pelos outros estados. Requer também um papel ativo em política internacional, priorizando as relações tanto com países em desenvolvimento como com países desenvolvidos. Como país de nível de desenvolvimento intermediário. A cooperação sul-sul beneficia o bloco UNASUL (fortalece como países latinos) (13) (14).

A União das Nações Sul-Americanas (Unasul) é a ilustração mais recente das relações entre saúde e política externa na região das Américas. Outras experiências de início anterior e já com extensa lista de resultados, podem ser incluídas no rol de processos sub-regionais de cooperação em saúde, sempre em torno da conformação de blocos de países: Mercosul, Organização do Tratado de Cooperação Amazônica (OTCA), Comunidade Andina de Nações (CAN) e Sistema de Integração Centro-Americana (SICA). História pródiga em dificuldades na formulação de consensos e limitações na obtenção de resultados em curto prazo, mas que reforça a tese da interdependência entre cooperação internacional, política setorial e política externa (15).

Com os artigos da análise bibliográfica foi possível identificar que os países da cooperação técnica internacional em Bancos de Leite Humano desenvolvida pelo Brasil, reconhecem que é uma estratégia que realmente contribui para redução da mortalidade na infância, mesmo que em territórios diferentes, os benefícios do banco de leite influenciam na qualidade de vida de neonatos, e ainda mais impacto para aqueles que condições de cuidado intensivo (8). 
O empoderamento social dentro de uma perspectiva nutritiva passa por doadoras que em sua ação de doar, salva vidas. São essas mulheres que, por meio da doação solidarizam e geram um impacto social contra a desnutrição e a redução da mortalidade.

A Rede Global de Leite Humano é a maior articuladora para o sucesso da política pública em amamentação no Brasil, política essa que faz o enfrentamento da mortalidade infantil, contudo é possível afirmar que o protagonismo feminino movimenta todas as ações que cooperam para a redução da mortalidade infantil.

Não há política de amamentação sem protagonismo e altruísmo das mulheres. $\mathrm{O}$ altruísmo é o motivo mais frequente dentro dessa ação, para a maioria das mulheres "o desejo de ajudar os outros" favorece a prática da doação (16).

Na Carta de Brasília 2005, instituiu diretrizes para os países internacionalizassem a ação do Banco de Leite Humano para construção de uma rede na América Latina e Caribe. Tais países necessitam expandir o conhecimento acerca da Rede Brasileira de Bancos de Leite Humano e todos os impactos positivos do processo (8).

Para a Fiocruz, a cooperação em saúde tem orientação de caráter solidário e ético para uma melhor saúde global e forma equitativa, embasado nas políticas públicas de saúde, que tem o objetivo da qualidade de vida da população (8).

Essa rede brasileira é considerada uma das mais complexas e eficientes de todo o mundo, sendo até um instrumento nacional para lidar com um dos desafios da primeira infância. Já na Carta de Brasília 2010 aborda as transformações que as redes de banco de leite trouxeram para a população destes países, além de considerações acerca dos benefícios em longo prazo e continuidade do projeto nos governos da América Latina (12).

O país cooperante exporta uma política pública e sua tecnologia, mediante os benefícios internos, e torna-se atrativo para os países em desenvolvimento pela efetividade e baixo custo. Esta ação pode ser vista como uma consolidação de políticas, ampliação de conhecimentos e diálogo intersetorial (12) (13).

A cooperação sul-sul desenvolveu ao longo dos anos um discurso, que tem como princípio a solidariedade e redução das desigualdades destes países. A equidade, justiça e solidariedade devem ser priorizadas no processo de desenvolvimento da cooperação sul-sul (14).

A cooperação sul-sul abrange uma interação econômica, comercial, social ou de outras naturezas que tem como ideal a vantagem mútua entre os países cooperantes, localizados 
no hemisfério sul. Com o aperfeiçoamento dos sistemas de saúde garante-se a qualidade em saúde e o acesso universal (17) (18) (19).

Para a discussão sobre a cooperação em saúde no Brasil são realizados fóruns, em que se ressaltam os principais tópicos sobre as cooperações entre os países em desenvolvimento, realiza-se o compartilhamento de desafios semelhantes entre os paísesmembros. São realizados intercâmbios de informações entre os integrantes, além de ciência e tecnologia (20).

Já na análise documental, o embasamento para as ideias de que a cooperação sul-sul relacionada à rede de banco de leite humano é de âmbito solidário e afirma as questões de proteção social e equidade entre os países em desenvolvimento, são os documentos: proibição da comercialização do leite humano nos estados partes e instituição do dia Mercosul de doação de leite humano (21) (22) (23).

Tais documentos explicam a importância do leite humano, que esta matéria prima que promove saúde, previne danos e melhora a qualidade de vida das crianças nos primeiros anos de vida, além de trazer benefícios para todo o ciclo vital, é adquirido por meio de doação, ressaltando a gratuidade do produto e declarando que é proibida a comercialização do leite humano (22) (23).

Nesse contexto podemos afirmar que são as mulheres que movimentam em favor da vida fato do leite ser um produto totalmente gratuito, tendo legislações que proíbam sua venda nas redistribuições a recém-nascidos prematuros e de baixo peso, faz com que essa ação seja não só a doação deum alimento, mas sim uma questão de sobrevivência desses neonatos.

E que abrange as principais estratégias que atenderam os ODM. Tal doação engloba o Mercosul, que contribui para a disponibilidade do leite humano. Os estados partes podem utilizar atividades simultâneas para promoção da celebração da data, mas é necessário que a participação ativa da população e atores sociais (22) (23).

\section{Conclusão}

O Brasil trabalha ativamente no contexto da política externa de diplomacia em saúde, articulada com a Agência Brasileira de Cooperação e a Fiocruz.

Na tentativa de realizar boas práticas e compartilhar saber no campo de cooperação técnica internacional em saúde, que é pautada em planejamento estratégico conjunto, não 
voltada a resultados exclusivamente imediatos, mas integrado na construção a médio e longo prazo. Focada no equilíbrio de interesses, com perspectiva de gerar processo que culminem na qualificação para promover autonomia técnica e científica dos países cooperantes, todo o esforço em cooperar tem como objetivo a garantia de direitos sociais e direito a saúde da criança.

A estratégia de criação e fortalecimento da Rede de Banco de Leite configurou uma ação para enfrentar os altos índices de mortalidade e morbidade infantil, trazendo um alinhamento com os ODM, e atualmente fazendo parte dos Objetivos de Desenvolvimento Sustentável.

A cooperação sul-sul tem se fortalecido com o passar dos anos e como política externa em saúde ganhou o campo de visibilidade no cenário de política pública internacional. Mesmo com os objetivos da inserção internacional e visibilidade global e das várias articulações multilaterais, a estratégia mantém um perfil solidário entre os países pactuados, pois o objetivo de redução da mortalidade é enfrentado como experiência exitosa.

E nesse aspecto de cooperação dos atores sociais a mulher é a maior protagonista e doadora dessa ação, pois ela é empoderada a amamentar seu filho e ainda tem a capacidade de doação para o enfrentamento da mortalidade, ou seja, o produto em evidência que é o leite materno, não é comercializado e está estritamente proibida sua venda como produto.

\section{Referências}

1. Almeida C, Campos RP, Buss P, Ferreira JR, Fonseca LE. A concepção brasileira de "cooperação sul-sul estruturante em saúde". R. Eletr. de Com. Inf. Inov. Saúde. 2010; 4(1):25-35. Disponível em: http://www6.ensp.fiocruz.br/radis/sites/default/files/pdf/aconcepcao-brasileira-de-cooperacao-sul-sul-estruturante-em-saude.pdf [Acesso em 1‥set.2017].

2. Puente CAI. A cooperação técnica horizontal brasileira como instrumento da política externa: a evolução da cooperação técnica com países em desenvolvimento - CTPD - no período 1995-2005. Brasília: FUNAG, 2010. Disponível em:

http://funag.gov.br/loja/download/715-

Cooperacao Tecnica Horizontal Brasileira como Instrumento da Polltica Externa A.pdf [Acesso em 1‥set.2017].

3. Pereira AD, Medeiros K. O prelúdio da cooperação sul-sul: da Conferência de Bandung à Conferência de Buenos Aires (1955-1978). I Seminário Internacional de Ciência Política Universidade Federal do Rio Grande do Sul. Porto Alegre, 2015. Disponível em: 
https://www.ufrgs.br/sicp/wp-content/uploads/2015/09/PEREIRA-MEDEIROS-2015-OPrel\%C3\%BAdio-Da-Coopera\%C3\%A7\%C3\%A3o-Sul-Sul.pdf [Acesso em 13.out.2017].

4. Milani CRS. Aprendendo com a história: críticas à experiência da Cooperação NorteSul e atuais desafios à Cooperação Sul-Sul. Caderno CRH. 2012; 25(65). Disponível em: http://www.redalyc.org/html/3476/347632188003/ [Acesso em 13.out.2017].

5. Agência Brasileira de Cooperação. Definição de cooperação sul-sul. Disponível em: http://www.abc.gov.br/ [Acesso em 23.set.2017].

6. Santos RF, Cerqueira MR. Cooperação sul-sul: experiências brasileiras na América do Sul e na África. História, Ciências, Saúde-Manguinhos. 2015, 22(1). Disponível em: http://www.scielo.br/pdf/hcsm/v22n1/pt 0104-5970-hcsm-22-01-00023.pdf [Acesso em 23.set.2017].

7. Almeida, $C$ et al. A concepção brasileira de "cooperação sul-sul estruturante em saúde”. RECIIS - R. Eletr. de Com. Inf. Inov. Saúde. Rio de Janeiro. 2010; 4(1):25-35. Disponível em: http://www6.ensp.fiocruz.br/radis/sites/default/files/pdf/a-concepcaobrasileira-de-cooperacao-sul-sul-estruturante-em-saude.pdf [Acesso em 23.set.2017].

8. Rabuffetti AG. Cooperação técnica internacional em bancos de leite humano: um estudo da horizontalidade nos projetos bilaterais. Rio de Janeiro: Programa de PósGraduação Profissional em Saúde Pública, Escola Nacional de Saúde Pública Sergio Arouca; 2014. Disponível em: https://www.arca.fiocruz.br/bitstream/icict/24399/1/252.pdf [Acesso em 1‥set.2017].

9. Agência Brasileira de Cooperação. Programa de bancos de Leite Humano/Amamentação: Alimentando a paz no mundo. Disponível em: https://www.youtube.com/watch?v=YyxDwDIXg6U [Acesso em 23.set.2017].

10. Pitas TM. O diálogo entre saúde e política externa na cooperação brasileira em bancos de leite humano Ciência \& Saúde Coletiva. 2017; 22(7): 2277-2286. Disponível em: http://www.scielo.br/pdf/csc/v22n7/1413-8123-csc-22-07-2277.pdf [Acesso em 23.set.2017].

11. Rede Brasileira de Bancos de Leite. Trajetória, Fiocruz, 2005.

Disponível em: http://www.redeblh.fiocruz.br/cgi/cgilua.exe/sys/start.htm?tpl=home [Acesso em 23.set.2017].

12. Pittas TM, Dri CF. O diálogo entre saúde e política externa na cooperação brasileira em bancos de leite humano. Ciência \& Saúde Coletiva. 2017; 22. Disponível em: http://www.scielosp.org/scielo.php?script=sci arttext\&pid=S1413$81232017000702277 \&$ lang=pt [Acesso em 23.set.2017].

13. Santana JP, Garrafa V. Cooperação em saúde na perspectiva bioética. Ciênc. Saúde Coletiva. 2013; 18(1):129-137. Disponível em: http://pesquisa.bvsalud.org/brasil/resource/pt/lil-662873 [Acesso em 14.out.2017]. 
14. Santana JP. Dimensões bioéticas da cooperação internacional em saúde: ainda uma questão polêmica? Ciênc. Saúde Coletiva. 2017; 22(7). Disponível em: http://pesquisa.bvsalud.org/brasil/resource/pt/biblio-859766 [Acesso em 14.out.2017].

15. Santana JP. Um olhar sobre a cooperação sul-sul em Saúde. Ciênc. Saúde Coletiva. 2011;16(6): 2993-3002. Disponível em: http://pesquisa.bvsalud.org/brasil/resource/pt/lil$\underline{591253}$ [Acesso em 14.out.2017].

16. Alencar LCE, Seidl EMF. Doação de leite humano: experiência de mulheres doadoras. Revista de saúde pública. 2009; 43(1):70-77. Disponível em: http://www.revistas.usp.br/rsp/article/view/32569 [Acesso em 9.jan.2018].

17. Buss PM, Ferreira JR. Diplomacia da saúde e cooperação sul-sul: as experiências da Unasul saúde e do Plano Estratégico de Cooperação em Saúde da Comunidade de Países de Língua Portuguesa. RECIIS. 2017; 11(1):13. Disponível em: http://pesquisa.bvsalud.org/brasil/resource/pt/biblio-833248 [Acesso em 14.out.2017].

18. Santana JP. Paradoxos da cooperação em saúde. Rev. Hum. Méd. 2013; (3):41-45. Disponível em: http://pesquisa.bvsalud.org/brasil/resource/pt/biblio-832210 [Acesso em 14.out.2017].

19. Perez FA. Panorama da cooperação internacional em saúde em países da América do Sul. São Paulo: Programa de Pós-Graduação em Saúde Pública, Univerisade de São Paulo, 2012. Disponível em: http://pesquisa.bvsalud.org/brasil/resource/pt/lil-666598 [Acesso em 14.out.2017].

20. Roa AC. A agenda de Cooperação Sul-Sul em Saúde do Fórum IBAS - Índia, Brasil e África do Sul. Rio de Janeiro: Programa de Pós-Graduação em Saúde Pública, Escola Nacional de Saúde Pública Sergio Arouca, 2014. Disponível em: http://pesquisa.bvsalud.org/brasil/resource/pt/lil-744970 [Acesso em 14.out.2017].

21. Santana JP. Cooperação Sul-Sul na área da saúde: dimensões bioéticas. Brasília. Ciência \& Saúde Coletiva. 2012; 18(1):129-137. Disponível em: http://repositorio.unb.br/bitstream/10482/12637/4/ARTIGO Coopera\%C3\%A7\%C3\%A3oSa \%C3\%BAdePerspectivaBio\%C3\%A9tica.pdf [Acesso em 14.out.2017].

22. Mercosul. Resolução $n^{\circ} 09$ de 2011. Proibição da comercialização do leite humano nos estados partes, 2011. Disponível em http://www.inmetro.gov.br/barreirastecnicas/PDF/RES 009-2011.pdf [Acesso em 14.out.2017]

23. Mercosul. Resolução $n^{\circ} 08$ de 2012. Instituição do Dia Mercosul de doação de leite humano. 2012. Disponível em http://www.redeblh.fiocruz.br/media/mercosul082012.pdf [Acesso em 14.out.2017] 
Cuadernos Iberomericanos

\section{Como citar este artigo:}

Santos MG. A importância da cooperação sul-sul em saúde no processo de implantação da Rede Latinoamericana de Banco de Leite Humano. Revista Cadernos Ibero-Americanos de Direito Sanitário. 2018 jan./mar, $7(1): 263-280$. 